\title{
A AMOSTRAGEM DE SUCATAS E A PRESENÇA DE CLORO NOS CONTAMINANTES DE ORIGEM ORGÂNICA *
}

\author{
Pedro Jorge Walburga Keglevich de Buzin ${ }^{1}$ \\ Rejane Maria Candiota Tubino² \\ Nestor Cezar Heck ${ }^{3}$ \\ Antônio Cezar Faria Vilela 4
}

\begin{abstract}
Resumo
A presença de elementos residuais nas sucatas ferrosas pode influenciar a qualidade do aço produzido na aciaria elétrica. Além disto, o cloro existente nos materiais orgânicos que acompanham as sucatas leva a problemas de ordem ambiental. Por este motivo, o acompanhamento destes contaminantes através de métodos de amostragem de sucata se torna uma tarefa importante na aciaria elétrica. Neste trabalho são apresentados alguns procedimentos de amostragem de sucata, bem como uma análise comparativa de sucatas processadas por moinhos do tipo shredder e sucatas sem processamento. Os resultados mostraram um aumento da densidade e a redução do teor de contaminantes (matéria orgânica, alumínio e aço inox) para a sucata processada por shredder em comparação com a sucata sem processamento. Complementando, é apresentado um perfil da concentração de cloro em diversos materiais orgânicos comumentemente encontrados nas sucatas.
\end{abstract}

Palavras-chave: Amostragem; Contaminantes; Sucatas ferrosas; Cloro.

\section{SCRAP SAMPLING AND THE CHLORINE EXISTING IN ORGANIC CONTAMINANTS}

\begin{abstract}
The presence of residual elements in ferrous scrap may influence the steel quality produced in electric steelmaking shop. In addition, the chlorine existing in organic materials associated to scrap leads to environmental problems. For this reason, the monitoring of these contaminants through scrap sampling methods becomes an important task in the electric steelmaking. In this work, some procedures of scrap sampling are presented, as well as a comparative analysis of scrap processed by shredder and scrap without processing. Results showed an increase in density and reduction of contaminant levels (organic matter, aluminium, and stainless steel) for scrap processed by shredder compared to unprocessed scrap. In addition, a chlorine concentration profile of several organic materials commonly found in scrap is presented.
\end{abstract}

Keywords: Sampling; Contaminants; Ferrous scrap; Chlorine.

\footnotetext{
Dr., PPG3M, Laboratório de estudos ambientais, LEAmet, UFRGS.

Dra. PPG3M, Laboratório de estudos ambientais, LEAmet, UFRGS.

Dr-Ing. PPG3M, Núcleo de termodinâmica. computacional para a metalurgia, NTCm, UFRGS.

Dr-Ing. PPG3M, Laboratório de siderurgia, LASID, UFRGS.
} 


\section{INTRODUÇÃO}

O principal tipo de carga metálica utilizada na aciaria elétrica é a sucata ferrosa, em geral acompanhada de percentuais variáveis de ferro-gusa e escorificantes. Por esta razão, a operação do pátio de sucatas corresponde à primeira etapa do processo e as atividades deste setor são essenciais para garantir a estabilidade da composição e o contínuo fornecimento de matéria-prima para o forno elétrico a arco (FEA), além de contribuir para o bom resultado final no que se refere à qualidade do aço produzido, ao custo, à segurança e ao meio ambiente.

Algumas sucatas possuem em sua composição elementos residuais como cobre e estanho, que uma vez incorporados ao aço são de difícil remoção. Além destes metais, a presença de outros elementos como o chumbo, cádmio, zinco e compostos contendo cloro, influenciam tanto em aspectos ambientais do processo quanto na destinação do pó de aciaria elétrica (PAE) - já que é neste resíduo que estes metais e o cloro, na forma de cloretos, tendem a se concentrar em sua maior parte.

A questão da aferição da qualidade das sucatas, em função da maior ou menor quantidade de impurezas presentes, tem levado à adoção de critérios de classificação, como por exemplo o ESGS - European Scrap Grading System [1], onde as sucatas são classificadas de acordo com a origem e várias outras características, tais como os níveis de metais residuais. Exemplos desta modalidade de classificação encontram-se descritos na Tabela 1.

Tabela 1. Classificação de sucatas ferrosas segundo ESGS (\% em massa)

\begin{tabular}{|c|c|c|c|c|c|c|c|c|c|}
\hline Categoria & Espec & Descrição & $\begin{array}{c}\text { Espes } \\
(\mathrm{mm})\end{array}$ & $\begin{array}{l}\text { Dimensões } \\
\text { L x I x h(m) }\end{array}$ & $\begin{array}{c}\text { Densidade } \\
\left(\mathrm{t} / \mathrm{m}^{3}\right) \\
\end{array}$ & $\begin{array}{c}\text { Estéreis } \\
(\%)\end{array}$ & Cu (\%) & Sn (\%) & $\begin{array}{c}\mathrm{Cr}+\mathrm{Ni}+\mathrm{Mo} \\
(\%)\end{array}$ \\
\hline \multirow{2}{*}{$\begin{array}{l}\text { Sucata } \\
\text { antiga }\end{array}$} & E3 & $\begin{array}{l}\text { Sucata } \\
\text { grossa }\end{array}$ & $\geq 6$ & $<1,5 \times 0,5 \times 0,5$ & $\geq 0,6$ & $\leq 1,0$ & $\leq 0,250$ & $\leq 0,01$ & $\Sigma \leq 0,250$ \\
\hline & E1 & $\begin{array}{l}\text { Sucata } \\
\text { fina }\end{array}$ & $<6$ & $<1,5 \times 0,5 \times 0,5$ & $\geq 0,5$ & $\leq 1,5$ & $\leq 0,400$ & $\leq 0,02$ & $\Sigma \leq 0,300$ \\
\hline \multirow{3}{*}{$\begin{array}{l}\text { Sucata } \\
\text { nova } \\
\text { Sem } \\
\text { pintura, } \\
\text { baixo nível } \\
\text { de } \\
\text { residuais }\end{array}$} & E2 & $\begin{array}{l}\text { Sucata } \\
\text { nova } \\
\text { grossa }\end{array}$ & $\geq 3$ & $<1,5 \times 0,5 \times 0,5$ & $\geq 0,6$ & $\leq 0,3$ & \multicolumn{3}{|c|}{$\Sigma \leq 0,300$} \\
\hline & E8 & $\begin{array}{l}\text { Sucata } \\
\text { nova } \\
\text { fina }\end{array}$ & $<3$ & $<1,5 \times 0,5 \times 0,5$ & $\geq 0,4$ & $\leq 0,3$ & \multicolumn{3}{|c|}{$\Sigma \leq 0,300$} \\
\hline & E6 & $\begin{array}{l}\text { Sucata } \\
\text { nova fina } \\
\text { prensada }\end{array}$ & $<3$ & $<1,5 \times 0,5 \times 0,5$ & $\geq 1,0$ & $\leq 0,3$ & \multicolumn{3}{|c|}{$\Sigma \leq 0,300$} \\
\hline $\begin{array}{l}\text { Sucata } \\
\text { Shredder }\end{array}$ & E40 & $\begin{array}{l}\text { Sucata } \\
\text { triturada } \\
\text { Class. }\end{array}$ & & $<0,20 \mathrm{~m}$ & $>0,9$ & $<0,4$ & $\leq 0,250$ & $\leq 0,02$ & ------- \\
\hline \multirow{2}{*}{$\begin{array}{l}\text { Sucata de } \\
\text { cavacos }\end{array}$} & E5H & Cavacos & \multicolumn{7}{|c|}{ É necessário análise preliminar } \\
\hline & E5M & Cavacos & ----- & ------ & ------ & ------- & $\leq 0,400$ & $\leq 0,03$ & $\Sigma \leq 1,0$ \\
\hline \multirow{2}{*}{$\begin{array}{l}\text { Sucata } \\
\text { com alto } \\
\text { teor de } \\
\text { residuais }\end{array}$} & EHRB & $\begin{array}{l}\text { Sucata } \\
\text { Geral }\end{array}$ & ----- & $<1,5 \times 0,5 \times 0,5$ & $\geq 0,5$ & $<1,5$ & $\leq 0,450$ & $\leq 0,03$ & $\Sigma \leq 0,35$ \\
\hline & EHRM & $\begin{array}{l}\text { Peças me- } \\
\text { cânicas }\end{array}$ & ------ & $<1,5 \times 0,5 \times 0,5$ & $\geq 0,6$ & $<0,7$ & $\leq 0,400$ & $\leq 0,03$ & $\Sigma \leq 1,0$ \\
\hline $\begin{array}{l}\text { Sucata pro- } \\
\text { cessada de } \\
\text { incinerado- } \\
\text { res de RSU }\end{array}$ & E46 & $\begin{array}{l}\text { Sucata de } \\
\text { Incinera- } \\
\text { dor }\end{array}$ & & $<0,20 \mathrm{~m}$ & $\geq 0,8$ & $\begin{array}{l}\text { Teor de } \\
\mathrm{Fe}>92 \%\end{array}$ & $\leq 0,500$ & $\leq 0,07$ & -------- \\
\hline
\end{tabular}

Fonte: adaptado de Birat et al. [2] e European Steel Scrap Specification, ESGS.

A avaliação da composição química das sucatas nas usinas é um processo que não é muito fácil de ser executado. Existe uma ampla diversidade das fontes geradoras e dos tipos de sucata. Além disso, o grande fluxo desta matéria-prima que chega diariamente, geralmente em cargas misturadas ou não classificadas, dificulta esta avaliação [3]. Desta forma, a prática da amostragem de sucatas ferrosas já vem 
sendo desenvolvida de longa data, tendo em vista a importância da composição das sucatas para a fabricação do aço, em especial na aciaria elétrica. Além disto, nos dias de hoje, o entendimento da influência das matérias-primas nos produtos fabricados e nos impactos ambientais dos processos siderúrgicos tem alcançado maior relevância, uma vez que a correta gestão destes impactos afeta economicamente o processo como um todo.

A disponibilidade das diversas sucatas no mercado, a escala de produção bem como fatores econômicos, geográficos e logísticos também podem influenciar nas decisões de aquisição dos lotes de sucata. Apesar de poderem ser classificadas por tipos, as sucatas ferrosas caracterizam-se por ser uma matéria-prima que apresenta grande variabilidade, tanto em função de sua qualidade como também em razão do tamanho e diversidade dos objetos/materiais presentes. Como consequência, o controle do ingresso no processo de elementos residuais que afetam a qualidade do aço obtido, além de elementos deletérios ao meio ambiente como o cloro, provindos da sucata, são atividades importantes no dia a dia de uma aciaria elétrica.

Por esta razão, alguns sistemas ou métodos de amostragem de sucata foram desenvolvidos. Dentre estes, pode-se citar o procedimento de amostragem proposto por Brown [4]. Neste método é sugerida uma metodologia de amostragem e avaliação de sucatas ferrosas com foco na avaliação de elementos residuais (especialmente Cu e Sn); para uma avaliação satisfatória de uma carga de sucata com relação a estes elementos muitas vezes é necessário a retirada de um número expressivo de amostras. Geralmente, a quantidade de amostras coletadas é determinada pelos diferentes tipos e tamanhos das peças ou objetos existentes no lote de sucata avaliado, o que demanda um grande esforço e um tempo considerável, pois quanto maior a diversidade delas/destes, maior o número de amostras necessárias para a caracterização dos lotes. Para a tomada de amostras é necessária a coleta em pelo menos três pontos de uma carga, equidistantes, do topo ao fundo, coletando-se pelo menos seis amostras, com a massa total entre 22,7 e 45,4 kg. A massa total de amostras vai depender do tamanho das peças. Se, por exemplo, for uma carga de cavacos, a amostra pode ser menor. Brown também propõe uma metodologia na qual toda a amostra é convertida em óxidos, em alta temperatura, inclusive os elementos residuais, sendo então os elementos analisados através de seus óxidos.

Alternativamente, pode-se efetuar a redução do tamanho das peças da amostra em pedaços de forma que passem nas aberturas de uma tela ou peneira de $12,7 \mathrm{~mm}$. Para este objetivo é utilizado um equipamento shredder que possa processar de 2,2 a $226 \mathrm{~kg}$ de material em alguns minutos. Da amostra cominuída e homogeneizada é então retirada a massa de 724 gramas, que representará a amostra a ser ensaiada. Esta porção é então colocada em um cadinho onde é feita sua ignição com auxílio inicial de gás natural e adição de oxigênio na taxa de 2 $\mathrm{L} / \mathrm{min}$. O botão de óxidos resultante é posteriormente cominuído em tamanhos passantes na peneira de $0,149 \mathrm{~mm}$ e amostras são retiradas para análise.

Por outro lado, na amostragem de sucatas pode-se também, em analogia, considerar a técnica de retirada de amostras de resíduos em pilhas, indicada pela norma ABNT NBR 10.007:2004 [5]. Para montes ou pilhas de resíduos, é recomendado por esta norma a retirada de amostras de pelo menos três seções (do topo, do meio e da base). Em cada seção devem ser coletadas quatro amostras eqüidistantes. Tendo em vista a impossibilidade de utilizar amostradores específicos, uma alternativa seria o desmonte da pilha para a obtenção das amostras. Também é 
indicado que uma vez obtidas as amostras, as mesmas, após homogeinização, podem ser reduzidas por quarteamento. Técnica semelhante de redução de amostras também é descrita detalhadamente na norma ASTM C702/C702M-11 [6].

Outra metodologia para amostragem de sucatas é a norma ASTM E701-80 (2010) [7], que descreve procedimentos para avaliar sucatas ferrosas recolhidas de resíduos sólidos urbanos, compreendendo métodos físicos e químicos. Tendo em vista a origem da sucata, esta norma recomenda cuidados com a segurança e higiene na condução de testes nas sucatas.

Para amostragem de um lote de sucata a norma ASTM E701-80 determina a coleta de pelo menos uma amostra bruta de sucata solta, com um volume de $7 \mathrm{ft}^{3}$ (aprox. 0,2 $\mathrm{m}^{3}$ ), ou seja, um tambor de 200 litros aproximadamente de amostra. Um guia para determinar 0 número de amostras brutas necessárias para a caracterização de um dado lote de material e metodologia para a preparação da amostra bruta pode ser visto na norma ASTM E122-09e1 [8]. Após a coleta da amostra bruta, seca-se a mesma ao ar, promovendo-se a sua distribuição num piso seco e limpo durante 24 horas, numa espessura de uma camada. A amostra deve ser protegida de eventuais contaminações por poeiras e detritos.

A seguir, transforma-se a amostra bruta em quatro amostras por quarteamento. Para preparação de amostra bruta de sucatas embaladas (enfardadas) toma-se no mínimo duas embalagens. Após esta divisão da amostra bruta, prossegue-se a análise do lote através de vários procedimentos. Um resumo dos procedimentos e análises efetuadas, previstos na norma ASTM E701-80, pode ser visto na sequência e um esquema para a amostragem de sucatas recolhidas de resíduos sólidos urbanos é observado na Figura 1:

- amostra bruta com volume de 200 litros (pelo menos uma);

- procedimentos de amostragem e $n^{\circ}$ de amostras brutas estabelecido em acordo;

- amostra bruta transformada em quatro subamostras, por quarteamento;

- todas as partes da amostra bruta são utilizadas;

- avaliação densidade: todas as subamostras AM 01 a AM 04;

- avaliação combustíveis: AM 01 e AM 03;

- análise química para indústria (exceto desestanhado): AM 01 e AM 03;

- análise fração magnética: AM 02 e AM 04;

- Análise química de estanho: separação manual de "latas e outros" das AM 02 e AM 04, para posterior quantificação e análise.

Amostra bruta

$\sim 200 \mathrm{~L}$ (tambor)
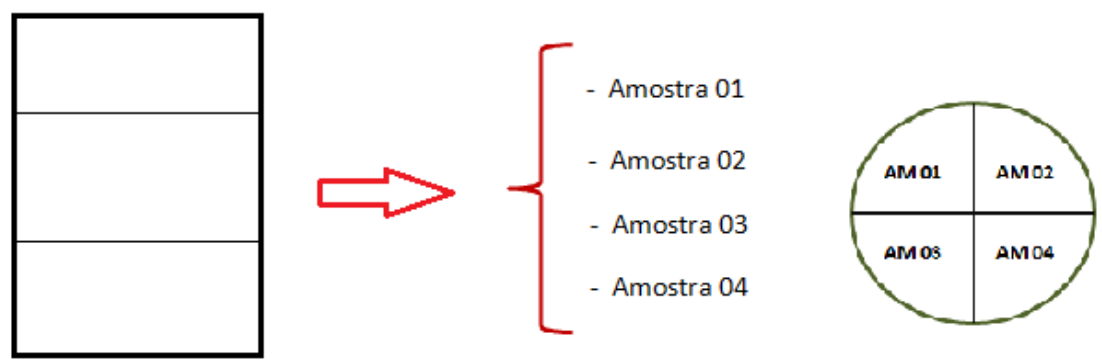

Figura 1. Esquema amostragem ASTM E 701 - 80 (2010). 
Tendo em vista o anteriormente exposto, verifica-se que a amostragem das sucatas e avaliação da sua composição é uma questão sempre presente nos processos de aciaria elétrica. Desta forma, os objetivos deste trabalho são: (i) efetuar uma comparação entre amostras de sucata mista e sucata processada por moinho tipo shredder e (ii) levantar um perfil da presença de cloro em impurezas orgânicas comumente existentes nas sucatas ferrosas.

\section{MATERIAIS E MÉTODOS}

Para a comparação de amostras de sucatas, em relação aos materiais contendo elementos residuais e contaminantes orgânicos, utilizou-se para cada amostra um volume coletado de aproximadamente $130 \mathrm{~L}$. A seguir, cada amostra foi distribuída em grupos relevantes, de modo a quantificar grupos de materiais de interesse. Partindo do princípio de que o cloro entra no processo de aciaria elétrica principalmente através das impurezas de natureza orgânica, efetuou-se uma avaliação do teor de cloro de vários materiais que comumente acompanham as sucatas. A seleção destes materiais se deu em função de observações em pátios de sucatas de aciarias elétricas e classificação de amostras de sucatas de uma usina siderúrgica, recolhendo-se amostras de materiais orgânicos presentes.

Para a avaliação do teor de cloro foram avaliadas 8 amostras de borrachas, 8 amostras de polímeros variados (misturas de plásticos, espumas, etc.), 6 amostras de materiais variados (madeira, tecidos, papel) e 10 amostras de tintas removidas de sucatas e chapas metálicas através de raspagem. As análises foram efetuadas com a utilização da metodologia de piroidrólise [9].

\section{RESULTADOS E DISCUSSÃO}

\subsection{Comparação entre sucata processada por shredder e sucata mista}

Após a coleta das amostras de cada tipo de sucata (shredder e mista), os materiais foram separados em grupos sobre uma lona plástica, tendo sua massa aferida. Na Tabela 2 encontram-se os resultados da amostra de sucata processada por shredder e na Tabela 3 os dados da amostra de sucata mista, sem processamento.

Tabela 2. Classificação e distribuição de massa da amostra de sucata processada por shredder

\begin{tabular}{lcc}
\hline \multicolumn{1}{c}{ Tipo de sucata } & Massa $(\mathbf{k g})$ & total (\%) \\
\hline Sucata limpa & 88,295 & 64,85 \\
Sucata com tinta & 27,970 & 20,54 \\
Filtros de óleo $^{1}$ & 1,130 & 0,83 \\
Sucata com borracha $_{\text {Matéria orgânica }}^{1,985}$ & 1,46 \\
Sucata com cobre & 0,240 & 0,18 \\
Sucata de inox & 0,965 & 0,71 \\
Ferro fundido & 0,615 & 0,45 \\
Alumínio & 3,010 & 2,21 \\
Varrição (inertes + ferro $\left.^{2}\right)$ & 0,085 & 0,06 \\
\hline \multicolumn{1}{c}{ Total } & 11,860 & 8,71 \\
\hline \multicolumn{2}{c}{}
\end{tabular}

\footnotetext{
${ }^{1}$ Filtros de óleo provenientes de veículos automotores.

${ }^{2}$ Pequenas peças/partes metálicas.
} 
Tabela 3. Classificação e distribuição de massa da amostra de sucata mista

\begin{tabular}{|c|c|c|}
\hline Tipo de sucata & Massa (kg) & total (\%) \\
\hline Sucata limpa & 60,670 & 67,07 \\
\hline Sucata com tinta & 16,705 & 18,47 \\
\hline Filtros de óleo & 0,980 & 1,08 \\
\hline Sucata com borracha & 1,760 & 1,94 \\
\hline Matéria orgânica & 1,875 & 2,07 \\
\hline Sucata com cobre & 0,500 & 0,55 \\
\hline Sucata de inox & 2,950 & 3,29 \\
\hline Ferro fundido & 0,085 & 0,09 \\
\hline Alumínio & 2,980 & 3,29 \\
\hline Varrição (inertes + ferro) & 1,950 & 2,15 \\
\hline Total & 90,455 & 100,00 \\
\hline
\end{tabular}

Comparando-se os resultados, verifica-se a maior densidade da sucata processada por shredder em comparação com a sucata mista sem nenhum tipo de beneficiamento, considerando que foram coletados aproximadamente volumes iguais para ambas as amostras. Percebeu-se também percentuais de massa menores para matéria orgânica, alumínio e aço inox para a sucata processada por shredder. A massa de sucata considerada limpa também foi maior para a amostra de sucata processada por shredder. Destas observações, verifica-se a melhoria da qualidade da sucata com o processamento por moinhos do tipo shredder.

Da análise dos materiais constantes nas amostras, percebeu-se que muitas vezes pode ocorrer a presença de cobre oriundo do enrolamento de sucata de motores elétricos, o que torna difícil a sua separação por meios magnéticos, tendo em vista que o rotor ou a carcaça geralmente é confeccionado em liga ferrosa, que é atraída pelo separador magnético, levando consigo o cobre. Ainda, este metal muitas vezes pode se encontrar na forma de fios e cabos arrastados ou aderidos a materiais com propriedades magnéticas, conforme se vê nas Figuras 2 e 3 . Complementando, uma das origens do chumbo e estanho (além do aço estanhado) é a liga de solda $\mathrm{Sn}-\mathrm{Pb}$ proveniente de resíduos de equipamentos eletroeletrônicos ou placas de circuito impresso (PCl), que estejam contaminando a sucata (Figura 3).

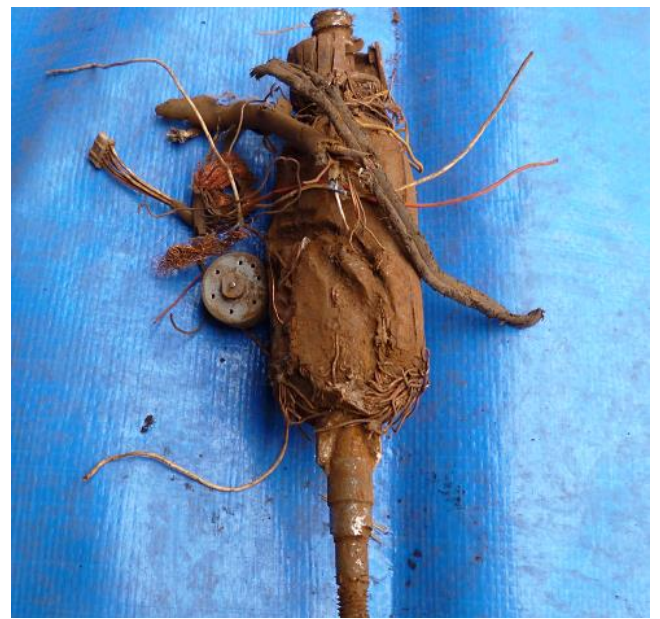

Figura 2. Cabos e rotor de motor elétrico.

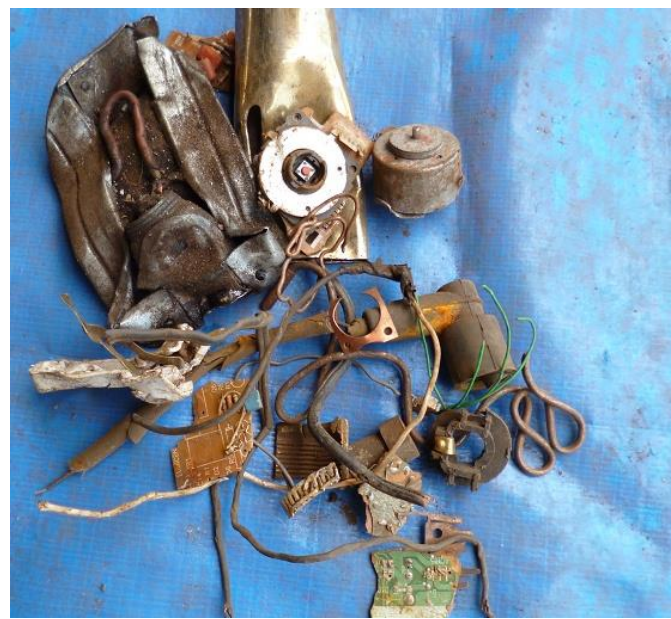

Figura 3. Cabos e resíduos de PCl.

Com relação aos materiais de origem orgânica, verificou-se que além das tintas aderidas às sucatas e materiais diversos como restos de madeira, polímeros, 
tecidos e outros, observa-se a existência de borrachas aderidas às partes metálicas ferrosas, como calços de amortecedores, mangueiras e outros objetos, a maioria originária de sucata automotiva. Este acoplamento dificulta a separação mecânica e magnética destes materiais da sucata. Um exemplo pode ser visualizado na Figura 4.

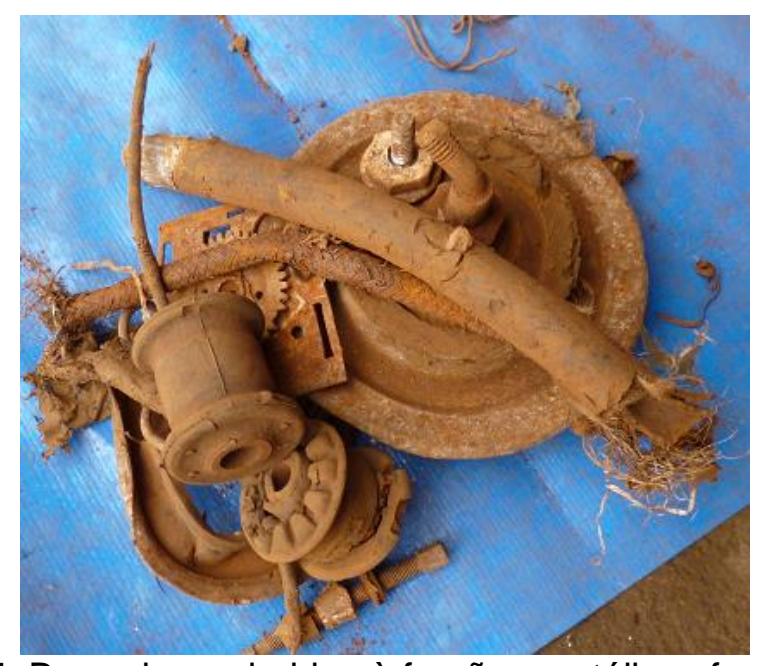

Figura 4. Borrachas aderidas à frações metálicas ferrosas.

Com relação aos recobrimentos de tinta, verificou-se que, mesmo para a fração de sucata considerada limpa, existiam peças/objetos com vestígios de tinta. 0 processamento por shredder tem a tendência de retirar parte deste recobrimento das peças, porém não é totalmente efetivo, conforme se vê na Figura 5.

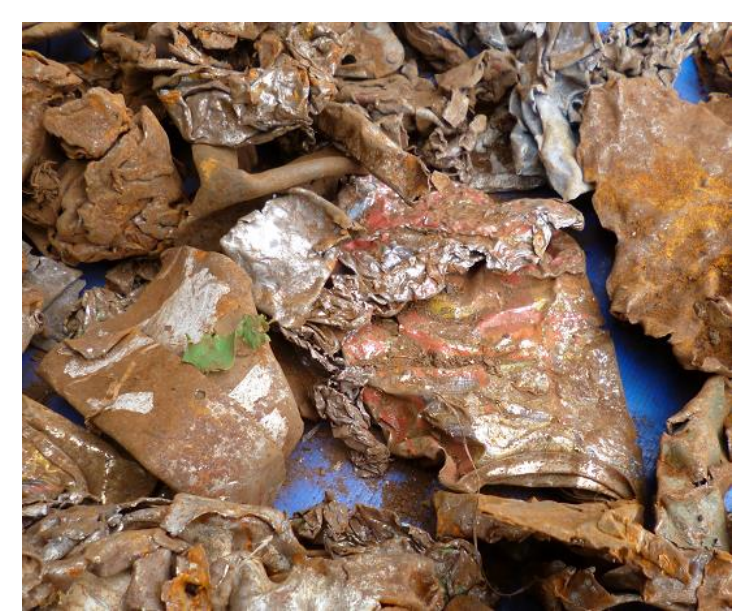

Figura 5. Sucata processada por shredder apresentando vestígios de tinta.

Outros tipos de materiais encontrados foram filtros de óleo de motores, os quais oferecem o risco de explosões quando carregados no FEA. Ainda, verificou-se a presença de sucata galvanizada em ambas as amostras. Tanto os filtros quanto a sucata galvanizada apresentam dificuldade de separação da sucata processada através dos meios convencionais (trituração, separação magnética, eletrostática).

\subsection{Resultado da avaliação do teor de cloro de impurezas orgânicas das sucatas.}


$\mathrm{Na}$ Tabela 4 encontram-se os dados obtidos da avaliação do teor de cloro de alguns materiais presentes nas sucatas. Os resultados estão expressos em $\mu \mathrm{g}$ Cloro/g (microgramas de cloro por grama de material ou ppm) e em porcentagem de cloro (\% em massa).

Tabela 4. Percentagem em massa de cloro de vários tipos de impurezas da sucata

\begin{tabular}{|c|c|c|c|}
\hline Amostra & Descrição da amostra & $\mu g$ Cloro/g & $\mathrm{Cl}(\%)$ \\
\hline AM01 & Resíduo borracha I & 333.436 & 33,34 \\
\hline AM02 & Resíduo borracha II & 1.598 & 0,16 \\
\hline AM03 & Resíduo borracha III & 600 & 0,06 \\
\hline AM04 & Resíduo borracha IV & 557 & 0,06 \\
\hline AM05 & Resíduo de borracha V & 2425 & 0,24 \\
\hline AM06 & Resíduo de borracha VI & 526 & 0,05 \\
\hline AM07 & Res. borracha amortecedor & 244 & 0,02 \\
\hline AM08 & Res. borracha retentor & 1.828 & 0,18 \\
\hline AM09 & Espuma de isolamento I & 18.301 & 1,83 \\
\hline AM10 & Polímero (plástico) & 181.687 & 18,16 \\
\hline AM11 & Polímero duro & 53911 & 5,39 \\
\hline AM12 & Polímero lacre conserva & 232.728 & 23,27 \\
\hline AM13 & Polímero espuma dura & 75.949 & 7,59 \\
\hline AM14 & Mistura plásticos II & 1.634 & 0,16 \\
\hline AM15 & Mistura plásticos I & 1.364 & 0,14 \\
\hline AM16 & Polímero (espuma) & 1.764 & 0,18 \\
\hline AM17 & Restos papel & 7.189 & 0,71 \\
\hline AM18 & Espuma de isolamento II & 18.920 & 1,89 \\
\hline AM19 & Restos fibra de vidro & 1.868 & 0,19 \\
\hline AM20 & Restos de madeira & 959 & 0,10 \\
\hline AM21 & Restos tecidos I & 36.958 & 3,69 \\
\hline AM22 & Restos tecidos II & 4.878 & 0,49 \\
\hline AM23 & Tinta automotiva I & 4.908 & 0,49 \\
\hline AM24 & Tinta automotiva II & 2.200 & 0,22 \\
\hline AM25 & Tinta lata de conserva I & 3.344 & 0,33 \\
\hline AM26 & Tinta lata conserva II & 3.189 & 0,32 \\
\hline AM27 & Tinta chapa computador & 1.247 & 0,12 \\
\hline AM28 & Tinta chapa pintada & 2.743 & 0,27 \\
\hline AM29 & Tinta latas de tinta & 1.606 & 0,16 \\
\hline AM30 & Tinta chapa (lata) & 1.451 & 0,15 \\
\hline AM31 & Tinta acrílica (restos lata) & 290 & 0,03 \\
\hline AM32 & Tinta lata spray & 2.206 & 0,22 \\
\hline
\end{tabular}

Ao observar-se os dados presentes na Tabela 4 percebe-se que o cloro encontra-se amplamente disseminado nas impurezas de natureza orgânica que 
normalmente acompanham as sucatas ferrosas. Os percentuais mais elevados encontrados referem-se a alguns tipos de borrachas e polímeros. Os maiores contribuidores de cloro nestes polímeros são as adições de PVC - policloreto de vinil, fórmula $\left(\mathrm{C}_{2} \mathrm{H}_{3} \mathrm{Cl}\right)_{\mathrm{n}}$, teor de cloro de $56,8 \%$. O PVC é o segundo termoplástico mais consumido no mundo e integra uma série de produtos de uso corrente [10]. Por exemplo, as borrachas nitrílicas co-polimerizadas com PVC podem conter entre 30 e $50 \%$ deste último [11]. Borrachas com PVC são também utilizadas em cabos elétricos e espumas de isolamento, existentes em sucatas de refrigeradores e veículos automotores.

Todas as tintas examinadas apresentaram cloro em sua constituição. Uma das fontes de cloro nas tintas são os silanos, compostos híbridos inorgânicoorgânico, usados como aditivos. Um exemplo de silano muito utilizado é o CloroPropil $\mathrm{Cl}-\mathrm{CH}_{2}-\mathrm{CH}_{2}-\mathrm{CH}_{2}-\mathrm{Si}\left(\mathrm{OCH}_{3}\right)_{3}$. Os silanos conhecidos como monossilanos possuem estrutura geral $\mathrm{X}_{3} \mathrm{Si}\left(\mathrm{CH}_{2}\right) \mathrm{nY}$, no qual $\mathrm{X}$ representa um grupamento metóxi ou etóxi capaz de hidrolisar e o $\mathrm{Y}$ representa um grupo organofuncional como clorina, amino, etc. Sua principal função é melhorar a união entre polímeros e minerais, aumentando a ligação, a resistência da tinta e a sua durabilidade. São muito utilizados na industria metal-mecânica e de linha branca, mas sua aplicação principal é na industria automotiva [12].

O processamento mecânico através do shredder e classificação posterior retira grande parte das impurezas de natureza orgânica que geralmente acompanham as sucatas ferrosas. Entretanto, observando-se sucatas processadas nos pátios das usinas e dados de composição do "fluff" ${ }^{3}$ [13], verifica-se que parte destas impurezas ainda permanecem após o processamento (arrastadas ou aderidas). Com esta constatação, pode-se concluir que mesmo com o processamento mecânico de sucatas, há um controle parcial da entrada do cloro no processo de aciaria elétrica e cuja eficiência vai depender do processo de prétratamento empregado e do tipo de sucatas processadas.

Considerando ainda que as sucatas de melhor qualidade no quesito cloro, como as de estamparia e fundidos, bem com o ferro gusa, possuem um valor de aquisição mais elevado, uma redução dos níveis de entrada de cloro no processo a valores muito baixos através do controle direto das matérias-primas é difícil em termos econômicos.

\section{CONCLUSÕES}

A preparação de sucata por shredder tende a melhorar tanto a densidade quanto a qualidade da sucata, aumentando o teor de ferro e reduzindo a entrada no processo de outros materiais contaminantes. Contudo, alguns tipos de impurezas orgânicas ou metais aderidos à partes de sucatas ferrosas apresentam dificuldade de serem retirados.

O cloro encontra-se amplamente disseminado nas sucatas, nas diversas frações de matéria orgânica, sendo que os maiores contribuidores são polímeros ou borrachas contendo PVC nas suas formulações.

\section{Agradecimentos}

\footnotetext{
${ }^{3}$ Resíduo proveniente do processamento de sucatas por moinhos tipo shredder.
} 

pesquisa.

Os autores agradecem à empresa Gerdau S/A pelo apoio dado a esta

\section{REFERÊNCIAS}

1 Europeam Steel Scrap Specification. The European Steel Association. [acesso 25 julho de 2015]. Disponível em www.eurofer.org/Facts\%26Figures/ws.res/eurSteelScrap Spec.pdf.

2 Birat J-P, Arion A, Faral M, Baronnet F, Marquaire, P-M, Rambaut P. Abatement of organic emissions in EAF exhaust flue gas. La Revue de Métallurgie-CIT, 2001; 98 (10): 839-854.

3 Vaz G D. Quantificação das Perdas de Ferro Metálico em Escórias de Forno Elétrico a Arco [dissertação de Mestrado].Rio de Janeiro: PUC-RIO; 2011.

4 Brown EE Inventor, Interlake Steel Corporation, assignor. Scrap Sampling Method. [United States Patent US 3372993]; 1968.

5 ABNT - Associação Brasileira de Normas Técnicas - Amostragem de Resíduos Sólidos - NBR 10007:2004.

6 ASTM - Americam Society for testing and materials - Standard Practice for Reducing Samples of Aggregate to Testing Size - ASTM C702/C702M-11.

7 ASTM - Americam Society for testing and materials - Standard Test Methods for Municipal Ferrous Scrap - ASTM E701-80 (2010).

8 ASTM - Americam Society for testing and materials - Standard Practice for Calculation Sample Size to Estimate, With Specific Precision, the Average for a Characteristic of a lot or Process - ASTM E122-09e1.

9 Antes FG, Duarte FA, Flores ELM, Paniz JNG, Flores EMM, Dressler VL. Preparo de Amostras de Combustíveis Fósseis por Piroidrólise para Determinação de Fluor e Cloro. Química Nova. 2010; 33(5): 1130-1134.

10 Rodolfo JRA, Mei CHI. Mecanismos da degradação e estabilização térmica do PVC. Polímeros Ciência e Tecnologia. 2007; 17(3): 263-275.

11 Garbim VJ. Borrachas - Tecnologias, características, compostos e aplicações. Rio de Janeiro: Editora Publit; 2012.

12 Ramos JT. Obtenção e caracterização de revestimentos protetores à base de silanos e sua ação combinada com tinta na proteção ao aço carbono [dissertação de Mestrado]. Porto Alegre: Ufrgs, PPGEM; 2009.

13 Reckziegel VN. Caracterização para o aproveitamento do resíduo de um triturador de sucata em uma usina siderúrgica [dissertação de Mestrado]. Porto Alegre: Ufrgs, PPGE3M; 2012. 